\title{
Passive cation permeability of turtle colon: Evidence for a negative interaction between intracellular sodium and apical sodium permeability
}

\author{
Kevin L. Kirk ${ }^{1}$ and David C. Dawson ${ }^{2}$ \\ 1 Nephrology Research and Training Center and Department of Physiology and Biophysics, \\ University of Alabama in Birmingham, Birmingham, AL 35294 \\ 2 Department of Physiology, University of Michigan Medical School, Ann Arbor, MI 48109, USA
}

\begin{abstract}
The role of intracellular sodium in the regulation of apical sodium permeability was investigated in an electrically "tight" epithelium, the turtle colon. In the presence of low mucosal sodium ( $3 \mathrm{mM}$ ) and serosal ouabain, an inhibitor of the basolateral sodium pump, the apical membrane retained a substantial amiloride-sensitive, sodium conductance and the basolateral membrane exhibited a barium-sensitive potassium conductance in parallel with a significant sodium (and lithium) conductance. In the presence of a high mucosal sodium concentration (114 mM), however, inhibition of active sodium absorption by ouabain led to a disappearance of the amiloridesensitive, transepithelial conductance that was due, at least in part, to a virtual abolition of the apical sodium permeability. Two lines of evidence indicate that this permeability decrease was dependent upon an increase in intracellular sodium content. First, raising the mucosal sodium concentration from 3-114 $\mathrm{mM}$ in the presence of ouabain reversibly inhibited the amiloride-sensitive conductance. The time course of the decline in conductance paralleled the apparent intracellular accumulation of sodium in exchange for potassium, which was monitored as a transient deflection in the amiloride-sensitive, short-circuit current. Second, the inhibitory effect of mucosal sodium-addition was markedly attenuated by serosal barium, which prevented the accumulation of sodium by blocking the electrically coupled, basolateral potassium exit. These results support the notion of a "negative feedback" effect of intracellular sodium on the apical sodium permeability.
\end{abstract}

Key words: Apical sodium permeability - Intracellular sodium - Basolateral sodium permeability - Basolateral potassium conductance - Lithium permeability

\section{Introduction}

Active sodium absorption across electrically "tight" epithelia (e.g., amphibian skin, mammalian and reptilian colon) consists of two steps. Sodium passively enters transporting cells via amiloride-sensitive channels located in the apical membrane and is actively extruded across the basolateral membrane via ouabain-sensitive, sodium-

Offprint requests to: $\mathrm{K}$. L. Kirk at the above address potassium pumps $[11,17,18]$. It is well established that if such tissues are bathed in sodium-rich solutions $(>100 \mathrm{mM}$ ) inhibition of the sodium pump by ouabain decreases, not only the rate of active sodium absorption, but also the sodium permeability of the apical membrane. Evidence for this additional effect of pump-inhibition comes from tracer flux studies which showed that apical sodium influx [2, $10,20]$ and transcellular sodium efflux [1] were reduced by inhibitors of pump turnover when the external sodium concentration was high. Also, several electrophysiologic studies demonstrated that pump-inhibition in the presence of high external sodium resulted in a marked reduction in the amiloride-sensitive, transepithelial conductance that was due to a decrease in the sodium conductance of the apical membrane $[13,14,29]$. Such observations have led to the notion of a "negative feedback" effect of elevated intracellular sodium concentration on the apical sodium permeability $[4,5,19,24,27]$, but the design of previous studies has not led to an unambiguous demonstration of the role of intracellular sodium accumulation in the observed permeability decrease. In fact, Eaton [9] recently concluded from measurements of intracellular sodium activity using sodiumselective electrodes that the apical sodium permeability of the rabbit urinary bladder was not reduced in the presence of elevated intracellular sodium levels.

In an earlier study of the turtle colon Thompson and Dawson [25] showed that the apical sodium influx was unaffected after inhibiting sodium absorption with ouabain if the mucosal sodium concentration was low $(2-16 \mathrm{mM})$. This observation raised the possibility that this epithelial preparation could be used to examine the requirement for intracellular sodium accumulation in the observed coupling between the apical sodium permeability and the turnover of the sodium pump. Accordingly, the experiments summarized here were designed to characterize the passive ion permeabilities of the ouabain-treated colon and to use this preparation to examine qualitatively the relationship between the apical sodium permeability and intracellular sodium content. The results confirm that, in the presence of low mucosal sodium ( $3 \mathrm{mM})$, apical sodium permeability is retained following inhibition of the sodium pump by ouabain. However, at a higher mucosal sodium concentration $(114 \mathrm{mM})$, apical sodium permeability was markedly reduced in the presence of ouabain. This decline in sodium permeability could be attenuated by serosal barium, which presumably reduced the intracellular accumulation of sodium by blocking the electrically coupled basolateral 
potassium exit. These results are qualitatively consistent with an inverse correlation between intracellular sodium content and apical sodium permeability.

\section{Methods}

Colons were removed from turtles (Pseudemys scripta), stripped of musculature as previously described [7], and mounted as flat sheets in lucite chambers such that the exposed tissue area was $5.2 \mathrm{~cm}^{2}$. In most experiments the serosal bathing solution contained $114 \mathrm{mM} \mathrm{Na}, 114 \mathrm{mM} \mathrm{Cl}$, $2.5 \mathrm{mM} \mathrm{K}, 2.5 \mathrm{mM} \mathrm{HCO}, 1.0 \mathrm{mM} \mathrm{Ca}, 5 \mathrm{mM}$ D-glucose, $5.0 \mathrm{mM}$ D-mannitol and $2.0 \mathrm{mM}$ pyruvate; and the mucosal solution was identical except that the sodium concentration was reduced to approximately $3 \mathrm{mM}$ by equimolar replacement of $\mathrm{NaCl}$ with choline-Cl. Similarly, sodium-free, lithium-containing solutions were prepared by equimolar replacement of sodium with lithium. The sodium, potassium, or lithium concentrations of all solutions were verified by flame photometry. All experiments were conducted at room temperature $\left(22^{\circ} \mathrm{C}\right)$ and the solutions vigorously stirred with air, the $\mathrm{pH}$ of both solutions being approximately 8.2 .

The lucite chambers were equipped with 4 agar bridges: two for measuring the transepithelial electrical potential difference (P.D.) and two for passing current across the tissues. In most cases the P.D. bridges were identical in ionic composition to the bathing solution in order to prevent junction potentials at the bridge-solution interfaces. The current-passing electrodes contained sodium-Ringer's as described above. The bridges were connected via appropriate electrodes to an electronic voltage clamp which could be adjusted to compensate for the fluid resistance between the tissue surfaces and the P. D. sensing electrodes. In all experiments the P.D. was clamped to $0 \mathrm{mV}$ and the short circuit current $\left(I_{\mathrm{sc}}\right)$ was continuously monitored on a strip chart recorder, The tissue conductance $\left(G_{\mathrm{T}}\right)$ was determined by measuring the change in transepithelial current due to a $500-1000 \mathrm{~ms}, 10 \mathrm{mV}$ change in clamping potential.

Transmural, unidirectional fluxes of sodium were measured as described previously [7] using ${ }^{22} \mathrm{Na}$ as the tracer. All flux determinations were carried out under short circuit conditions, and $I_{\mathrm{sc}}$ and $G_{\mathrm{T}}$ were continuously recorded. The transcellular components of the transepithelial sodium fluxes and $I_{\mathrm{sc}}$ were operationally defined as the amilorideinduced changes in these parameters. Previous studies performed in this laboratory have shown that transepithelial sodium flows measured either during active sodium absorption [7] or following the addition of ouabain [16] are confined to two parallel pathways; a transcellular pathway that is inhibited completely by mucosal amiloride $(0.1 \mathrm{mM})$ and an aqueous, paracellular pathway that has the selectivity of free solution.

In one set of experiments the unidirectional sodium influx from the mucosal solution into the cells of the colon was estimated using the technique described in detail by Thompson and Dawson [25]. The experimental conditions were identical to those described for the transepithelial flux and electrical measurements with the exception that the tissue area utilized for uptake measurements was approximately $1 \mathrm{~cm}^{2}$.

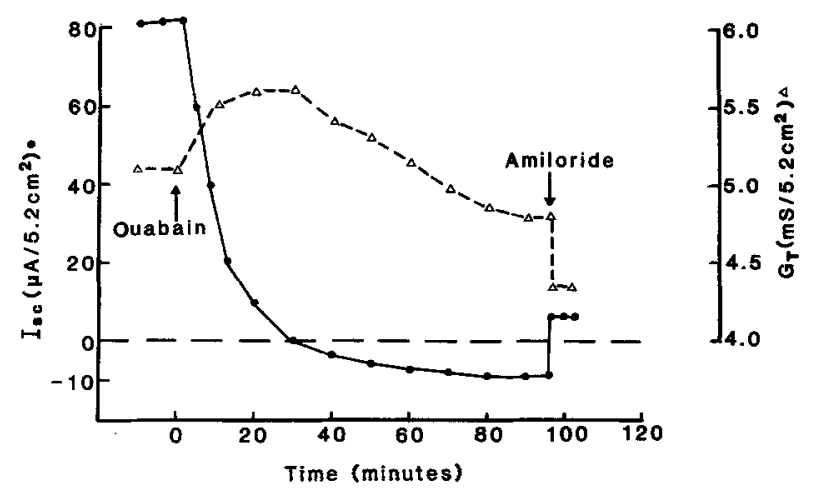

Fig. 1. Effects of ouabain on $I_{\mathrm{sc}}$ and $G_{\mathrm{T}}$ measured for a single tissue exposed to a serosa-to-mucosa, sodium gradient (114 to $3 \mathrm{mM}$ ). Serosal ouabain $(0.1 \mathrm{mM})$ and mucosal amiloride $(0.1 \mathrm{mM})$ were added at the arrows. Positive current represents positive charge flow from mucosa to serosa

\section{Results}

Effects of ouabain on transcellular sodium flow in the presence of low mucosal sodium

The aim of the experiment shown in Fig. 1 was to determine if a transcellular sodium conductance was retained in the presence of ouabain and a low mucosal sodium concentration $(3 \mathrm{mM})$. Plotted are the short circuit current $\left(I_{\mathrm{sc}}\right)$ and transepithelial conductance $\left(G_{\mathrm{T}}\right)$ measured for a single piece of colon bathed on the serosal side with $114 \mathrm{mM}$ sodiumRinger's and on the mucosal side with a solution containing $3 \mathrm{mM}$ sodium. Although not shown in Fig. $1, I_{\mathrm{sc}}$ measured prior to ouabain-addition is about $95 \%$ inhibited by mucosal amiloride [25] and measurements of transepithelial sodium flux have shown that this amiloride-sensitive $I_{\mathrm{sc}}$ is due to net sodium absorption from mucosa to serosa (data not shown). As shown in the figure, the serosal addition of ouabain caused $I_{\mathrm{sc}}$ to decline and, ultimately, to reverse in sign so that net positive charge flow was from serosa to mucosa. The "reversed" current was abolished by mucosal amiloride $(0.1 \mathrm{mM})$ suggesting that this current was due to net, transcellular movement of sodium down a chemical potential gradient from serosa to mucosa. $G_{\text {T }}$ rose transiently after the addition of ouabain and then declined to a value that was slightly less than the pre-ouabain level. The addition of mucosal amiloride further reduced $G_{\mathrm{T}}$, as expected if the reversed sodium flow was a conductive process that involved the amiloride-sensitive, sodium channels located in the apical membrane.

\section{Permselectivity of colonic cells during reversed cation flow}

1. Ion selectivity for steady-state reversed flow. The following experiments were performed to characterize further the permselectivity of colonic cells during reversed cation flow so that we could utilize this epithelial preparation to examine the putative coupling of the apical membrane sodium permeability to intracellular sodium levels. The selectivity of the amiloride-sensitive, reversed current pathway was investigated by first producing a reversed current with ouabain and a transepithelial sodium gradient and then replacing the sodium in both bathing solutions with lithium, potassium or rubidium on an equimolar basis. Of these 
Table 1. Reversed currents in the presence of transmural gradients of sodium or lithium

\begin{tabular}{|c|c|c|c|c|}
\hline & \multicolumn{2}{|l|}{$\mathrm{Na}^{+}$} & \multicolumn{2}{|l|}{$\mathrm{Li}^{+}$} \\
\hline & $I_{\mathrm{sc}}$ & $G_{\mathrm{T}}$ & $I_{\mathrm{sc}}$ & $G_{\mathrm{T}}$ \\
\hline Pre-amiloride & $-20.4 \pm 1.8$ & $5.40 \pm 0.26$ & $-17.1 \pm 1.4$ & $3.81 \pm 0.29$ \\
\hline Post-amiloride & $3.6 \pm 1.2$ & $4.17 \pm 0.19$ & $16.0 \pm 2.6$ & $6 \quad 3.41 \pm 0.29$ \\
\hline$\Delta$ & $24.0 \pm 2.4$ & $-1.23 \pm 0.05$ & $32.9 \pm 3.3$ & $3-0.40 \pm 0.06$ \\
\hline
\end{tabular}

Units: $I_{\mathrm{sc}}=\mu \mathrm{A} / 5.2 \mathrm{~cm}^{2} ; G_{\mathrm{T}}=\mathrm{mS} / 5.2 \mathrm{~cm}^{2}$.

$I_{\text {sc }}$ was measured before and after the addition of amiloride first in the presence of a serosa-to-mucosa gradient of sodium $(114 \mathrm{mM}$ to $3 \mathrm{mM}$ ) and then in the presence of an identical gradient of lithium Values are means $\pm \mathrm{SEM} ; n=8$

substitutes only lithium produced an amiloride-sensitive, reversed current. As shown in Table 1, the average amiloride-sensitive, reversed current was somewhat larger when carried by lithium while the amiloride-sensitive $G_{\mathbf{T}}$ was substantially less ${ }^{1}$.

\section{Evidence for a barium-sensitive, basolateral potassium con-} ductance. Although the ouabain-treated colon exhibits only a very small transcellular potassium conductance [15, 17], the presence of a substantial basolateral potassium conductance could be demonstrated by perturbing the potassium concentration of the serosal bathing solution. In Fig. 2, the middle trace shows a representative experiment in which reversed sodium flow was induced with ouabain in the presence of a serosa-to-mucosa sodium gradient. Abruptly raising the potassium concentration of the serosal bathing solution to $30 \mathrm{mM}$ produced a transient increase in the reversed current. The reversed current then returned to the control value with a half-time of about $30 \mathrm{~min}$. Washing the serosal surface with normal Ringer's $([\mathrm{K}]=2.5 \mathrm{mM})$ produced the opposite result, a transient decrease in the reversed current and a gradual return to the control level ${ }^{2}$. Transients in the reversed current induced by serosal potassium are consistent with the notion that in the absence of active sodium absorption the basolateral membranes of colonic cells retain a significant potassium conductance, whereas the apical

1 The amiloride-insensitive current that is measured in the presence of the transmural sodium or lithium gradient has two components. First, net cation flow through the paracellular pathway is driven from serosa to mucosa by the transepithelial diffusion E.M.F. that arises from the opposing choline and sodium (or lithium) gradients. Second, a relatively small current of opposite polarity is attributable to the active transport of some ion (s) other than sodium. This active transport component can be detected in the presence of amiloride, ouabain and identical bathing solutions (see Table 3) and, although the ionic basis of this current has not been established, it could represent active bicarbonate secretion [7]. Obviously, the disparity between the amiloride-insensitive currents measured in the presence of identical sodium or lithium gradients could be referable to different mobilities of these cations within the paracellular pathway as well as possible differential effects of sodium and lithium on the amiloride-insensitive, active transport process

2 Similar transients in $I_{\mathrm{sc}}$ could be produced by adding either the nitrate or methylsulfate salts of potassium whereas no changes in $I_{\mathrm{sc}}$ were observed following the addition of equi-osmolar amounts of sucrose, mannitol or choline chloride
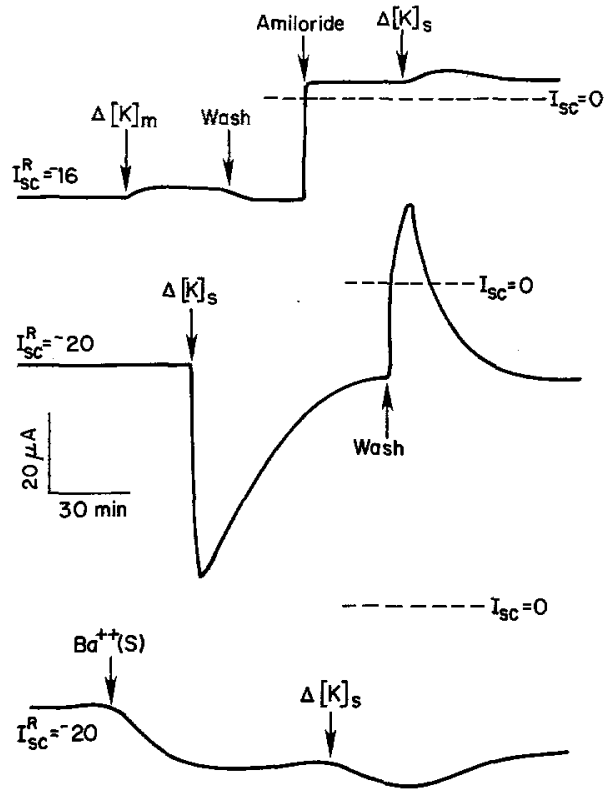

Fig. 2. Effects of raising mucosal or serosal potassium concentration on the reversed $I_{\text {sc }}$. Each of three tissues were exposed to serosal ouabain and a serosa to mucosa, sodium gradient (114 to $3 \mathrm{mM}$ ). Numbers at left indicate the initial, steady-state value of the reversed $I_{\text {sc }}$. All additions of potassium were in the form of a small volume of concentrated potassium chloride. Upper trace: raising the mucosal potassium concentration by $30 \mathrm{mM}$ had little effect on $I_{\mathrm{sc}}$. After washing and returning the mucosal potassium concentration to $2.5 \mathrm{mM}$ and then adding mucosal amiloride, raising the serosal potassium concentration by $30 \mathrm{mM}$ also had little effect on $I_{\mathrm{sc}}$. Middle trace: raising serosal potassium by $30 \mathrm{mM}$ induced a transient increase in the reversed $I_{\text {sc }}$. Subsequently washing and returning the serosal potassium concentration to $2.5 \mathrm{mM}$ induced a transient decrease in the reversed current. Bottom trace: serosal barium $(5 \mathrm{mM})$ blocked the transient increase in the reversed current that is induced by the addition of serosal potassium. Note that the modest deflection in $I_{\mathrm{se}}$ observed following the addition of barium is not due to an effect on the cellular sodium conductance, since barium has no effect on the amiloride-sensitive component of $I_{\mathrm{sc}}$ (see Table 2). The alternative explanation that barium influences the amiloride-insensitive $I_{\mathrm{sc}}$ is supported by our unpublished observations that similar current deflections are induced by barium in the presence of mucosal amiloride

membranes are relatively impermeable to potassium. According to this working hypothesis, the potassium current is zero under steady-state conditions because the potassium distribution across the basolateral membrane is at or near equilibrium. Raising serosal potassium alters the potassium E.M.F. across the basolateral membrane resulting in net potassium flow (and hence current flow) into the cell. At the apical membrane, however, this transcellular current must be carried by sodium ions which leave the cell in order to maintain macroscopic electroneutrality. The current is transient because the cell accumulates potassium (in exchange for sodium) and establishes a new quasi-equilibrium state when net potassium flow vanishes. This hypothesis is supported by results shown in the upper trace of Fig. 2. Raising the mucosal potassium concentration had little effect on the reversed current and the prior addition of mucosal amiloride prevented the effect of serosal potassium. In other experiments we observed that a potassium-induced 
Table 2. Effects of serosal barium on amiloride-sensitive $G_{\mathrm{T}}$ and reversed $I_{\mathrm{se}}$

\begin{tabular}{lllr}
\hline & $\Delta I_{\mathrm{sc}}$ & $\Delta G_{\mathrm{T}}$ & \multicolumn{1}{c}{$\Delta I_{\mathrm{sc}} / \Delta G_{\mathrm{T}}$} \\
\hline Pre-Ba $^{2+}$ & $25.6 \pm 3.4$ & $0.85 \pm 0.11$ & $31.0 \pm 3.7$ \\
$\mathrm{Ba}^{2+}$ & $24.2 \pm 3.1$ & $0.25 \pm 0.04$ & $103.0 \pm 7.1$ \\
Recovery & $21.8 \pm 1.8$ & $0.60 \pm 0.09$ & $38.8 \pm 5.6$ \\
\hline
\end{tabular}

Units: $\Delta I_{\mathrm{sc}}=\mu \mathrm{A} / 5.2 \mathrm{~cm}^{2} ; \Delta G_{\mathrm{T}}=\mathrm{mS} / 5.2 \mathrm{~cm}^{2} ; \Delta I_{\mathrm{sc}} / \Delta G_{\mathrm{T}}=\mathrm{mV}$ Amiloride-sensitive values of $I_{\mathrm{sc}}$ and $G_{\mathrm{T}}$ were measured for tissues exposed to ouabain and a serosa-to-mucosa sodium gradient $(114 \mathrm{mM}-3 \mathrm{mM})$ before the addition of $5 \mathrm{mM}$ serosal barium, after barium addition and after washing with barium-free Ringer's. In a parallel set of experiments (not shown) successive addition and removed of mucosal amiloride produced no change in the equivalent circuit parameters

Values are means $\pm \mathrm{SEM} ; n=5$

transient could be aborted at any time by adding amiloride to the mucosal bath (data not shown). The complete inhibition of these transients by mucosal amiloride implies that sodium dominates the conductance of the apical membrane under these conditions.

The bottom trace of Fig. 2 shows that the prior addition of $5 \mathrm{mM}$ barium to the serosal bath markedly attenuated the potassium-induced transient suggesting that the potassium entry proceeds via a barium-sensitive conductance. The data shown in Table 2 provide further evidence that serosal barium inhibits specifically a basolateral potassium conductance without influencing the cellular sodium conductance. In these experiments, the amiloride-sensitive conductance $\left(\Delta G_{\mathrm{T}}\right)$ and the amiloride-sensitive reversed current $\left(\Delta I_{\mathrm{sc}}\right)$ were measured first in the absence of serosal barium, then after the addition of serosal barium ( $5 \mathrm{mM}$ ) and again after washing off the barium. Serosal barium reversibly inhibited $\Delta G_{\mathrm{Y}}$ by more than $60 \%$, as expected if barium blocks a basolateral potassium conductance that exists in series with the amiloride-sensitive, apical sodium channel. Conversely, barium had no effect on $\Delta I_{\mathrm{sc}}$, as expected if the inhibitory effect of barium is specific for the basolateral potassium conductance. Consequently, the Thevenin E.M.F. for the amiloride-sensitive, transcellular pathway, operationally defined as $\Delta I_{\mathrm{sc}} / \Delta G_{\mathrm{T}}$, increased by over three-fold to a value that was indistinguishable from the transepithelial sodium E.M.F. $\left(E_{\mathrm{Na}}=95 \mathrm{mV}\right)$ calculated from the Nernst equation and the external sodium concentrations. The latter result implies that ouabain-treated cells are highly sodium-selective when the basolateral potassium conductance is reduced by barium.

Based on the preceding results, the equivalent circuit shown in Fig. 3 reasonably approximates the electrical properties of the amiloride-sensitive pathway of ouabaintreated cells that are exposed to a transepithelial sodium gradient. In this model the total amiloride-sensitive conductance is due entirely to the transcellular sodium and basolateral potassium conductances, as suggested by our experimental observations. The apical membrane is portrayed as having a single conductive path that represents the amiloride-sensitive, sodium channels $\left(r_{\mathrm{Na}}^{\mathrm{a}}\right)$. The basolateral membrane is portrayed as having as its sole conductive paths the parallel sodium and barium-sensitive, potassium conductances, represented by $r_{\mathrm{Na}}^{\mathrm{b} 1}$ and $r_{\mathrm{K}}^{\mathrm{b} 1}$, respectively. Note that the relatively large inhibitory effect of serosal barium

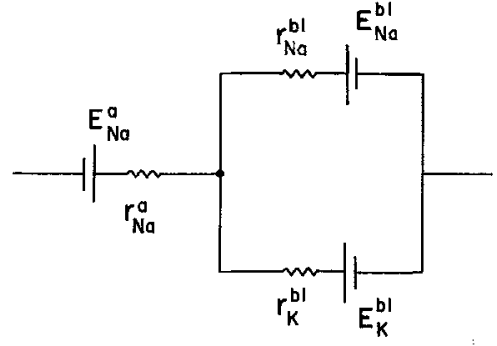

Fig. 3. Equivalent circuit for the amiloride-sensitive path of the turtle colon in the presence of ouabain and a transepithelial sodium gradient

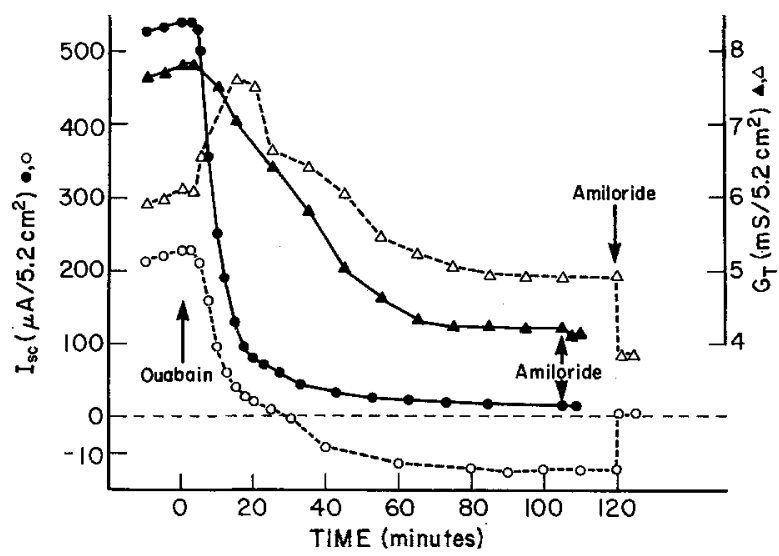

Fig. 4. Comparison of the effects of ouabain on $I_{\mathrm{sc}}$ and $G_{\mathrm{T}}$ measured in the presence (open symbols: serosa $-114 \mathrm{mM}$; mucosa $-3 \mathrm{mM}$ ) and absence (closed symbols: serosa and mucosa - $114 \mathrm{mM}$ ) of a transepithelial sodium gradient. $I_{\mathrm{sc}}$ and $G_{\mathbf{T}}$ are plotted for a single pair of tissues from the same animal. Amiloride $(0.1 \mathrm{mM})$ was added to the mucosal bath as indicated. Note the expansion of the current scale for negative currents

on the amiloride-sensitive conductance implies that the total cellular resistance is not dominated by the resistance of the apical membrane under these conditions.

\section{Influence of intracellular sodium accumulation on apical membrane sodium permeability}

1. Effect of ouabain on transcellular sodium flow in the presence of high mucosal sodium. The preceding experiments demonstrated that a significant apical sodium permeability was retained in the absence of active sodium absorption when the mucosal sodium concentration was low. The following experiments were designed to determine if pumpinhibition in the presence of high mucosal sodium abolishes the apical sodium permeability, as has been shown for other electrically tight epithelia, and to determine if this inhibition is related to the intracellular accumulation of sodium. Figure 4 is a plot of $I_{\mathrm{sc}}$ and $G_{\mathrm{T}}$ measured for two pieces of the same colon, one bathed on both sides in $114 \mathrm{mM}$ sodiumRinger's and the other exposed to a low mucosal sodium concentration. Again, $I_{\mathrm{sc}}$ measured prior to ouabain-addition is referable in either case to active sodium absorption from mucosa to serosa [25]. As shown previously in Fig. 1, ouabain-addition in the presence of a low mucosal sodium concentration resulted in a reversed current that was amil- 


potassium depletion) is required for the permeability decrease induced by high mucosal sodium and ouabain.

\section{Discussion}

Evidence for a sodium "leak" pathway in the basolateral membrane

The basolateral membrane of the ouabain-treated turtle colon exhibits a detectable sodium (and lithium) conductance, as evidenced by the transcellular reversed currents that were observed in the presence of transepithelial cation gradients. Similar reversed sodium currents that are blocked by amiloride and stimulated by antidiuretic hormone have been reported for the toad urinary bladder [8], suggesting the existence in both of these epithelia of a significant basolateral sodium "leak" in parallel with the sodium pump. Unfortunately, our results provide no information as to the magnitude of this "leak" during active sodium absorption, since inhibition of the pump could lead to quantitative or even qualitative changes in ion permeabilities [6] due to changes in cellular composition. However, tracer flux measurements performed on amphibian skins show that in some cases a substantial amiloride-sensitive, transepithelial sodium backflux can be detected during active sodium absorption [1, 3, 21], indicating that a significant sodium "leak" can exist in parallel with the basolateral sodium pump under some conditions.

\section{Influence of intracellular sodium accumulation on apical sodium permeability}

Our results are consistent with the notion of a "negative feedback" effect of intracellular sodium on apical sodium permeability. Specifically, raising the mucosal sodium concentration in the presence of ouabain led to a reversible decline in the cellular sodium permeability of the turtle colon that paralleled the intracellular accumulation of sodium in exchange for potassium. This inhibitory effect of mucosal sodium could be attenuated by serosal barium, which reduced the intracellular accumulation of sodium by blocking the obligatory, basolateral potassium exit. Turnheim et al. [28] similarly provided evidence for an inverse correlation between intracellular sodium concentration and apical sodium permeability in their studies of the rabbit colon, in which apical sodium permeability and intracellular sodium activity were estimated from the current-voltage relation of the amiloride-sensitive pathway. Conversely, Eaton [9] failed to detect any relationship between apical sodium permeability and intracellular sodium activity in the rabbit urinary bladder. Possibly, if the physiologic role of the putative "negative feedback" system is to minimize cell volume changes associated with increased sodium entry [24], such a mechanism is not required in the rabbit bladder, which normally has very low sodium absorptive rates and a low apical sodium permeability compared to either the mammalian or reptilian colon.

The nature of the coupling between cell sodium concentration and apical sodium permeability cannot be elucidated from the present work. Chase and Al-Awqati $[4,5]$ have provided evidence for the toad urinary bladder that inhibition of the apical sodium permeability results from increased cell calcium due to the diminution of the basolateral sodium gradient available to drive sodium-calcium exchange. It is also possible that the apical sodium permeability is modified by changes in other factors, e.g. intracellular potassium concentration, transmembrane voltages, or metabolic rate, [12, 22] that probably also vary under conditions of intracellular sodium accumulation and depletion.

\section{Passive permeability of colonic cells in presence of lithium}

Previously we showed that the turtle colon actively absorbs lithium [23] and that the active extrusion of lithium from transporting cells may occur via electroneutral, sodiumlithium exchange [16] driven by the basolateral sodium gradient. The present results confirm that lithium entry into colonic cells can occur via the amiloride-sensitive channel [26] and, in addition, show that ouabain-treated cells exhibit a detectable, basolateral permeability to conductive lithium flow. In the presence of identical cation gradients the amiloride-sensitive reversed current was greater for lithium than for sodium (Table 1), indicating that under these conditions the lumped membrane selectivity of the cellular, conductive path is about $1.37 \mathrm{Li}: 1.00 \mathrm{Na}$. In contrast, the conductance of the amiloride-sensitive path was markedly reduced in the presence of a lithium gradient. The apparent E.M.F. for the lithium current calculated from the ratio of the amiloride-sensitive $I_{\mathrm{sc}}$ and $G_{\mathrm{T}}$ was about $82 \mathrm{mV}$, a value which approaches that expected due to the applied lithium gradient. In light of the effect of barium on the apparent E.M.F. for reversed sodium flow (see Table 2), the equivalent circuit parameters measured in the presence of a transmural lithium gradient are consistent with the notion that in the presence of lithium the basolateral potassium conductance was reduced. Additional experiments (data not shown) reveal, in fact, that in the presence of a transmural lithium gradient the serosal potassium-induced transients are reduced or eliminated. The lithium-induced inhibition of basolateral potassium conductance could be one factor in previously reported inhibitory effects of serosal lithium on actively absorbing colons [23].

Acknowledgements. The authors express their appreciation to Melinda Lowy for assistance in performing these studies. This work was supported by Grant AM-29786 from the National Institute of Arthritis, Diabetes and Digestive and Kidney Diseases. D. C. Dawson is the recipient for Research Career Development Award AM00994 from the National Institutes of Health.

\section{References}

1. Bevevino LH, Lacaz-Vieira F (1982) Control of sodium permeability of the outer barrier in toad skin. J Membr Biol $66: 97-107$

2. Biber TUL (1971) Effect of changes in transepithelial transport on the uptake of sodium across the outer surface of the frog skin. J Gen Physiol 58:131-144

3. Biber TUL, Mullen TL (1976) Saturation kinetics of sodium efflux across isolated frog skin. Am J Physiol 231:995-1001

4. Chase HS, Al-Awqati Q (1981) Regulation of the sodium permeability of the luminal border of toad bladder by intracellular sodium and calcium. J Gen Physiol 77:693-712

5. Chase HS, Al-Awqati Q (1983) Calcium reduces the sodium permeability of luminal membrane vesicles from toad bladder. J Gen Physiol 81:643-665

6. Cox TC, Helman SI (1983) Effects of ouabain and furosemide on basolateral membrane $\mathrm{Na}$ efflux of frog skin. Am J Physiol 245:F312-F321 
7. Dawson DC (1977) $\mathrm{Na}$ and $\mathrm{Cl}$ transport across the isolated turtle colon: Parallel pathways for transmural ion movement. J Membr Biol 37:213-233

8. Dawson DC, Al-Awqati Q (1978) Induction of reverse flow of $\mathrm{Na}^{+}$through the active transport pathway in toad urinary bladder. Biochim Biophys Acta 508:413-417

9. Eaton DC (1981) Intracellular sodium ion activity and sodium transport in rabbit urinary bladder. J Physiol 316:527-544

10. Erlij D, Smith MW (1973) Sodium uptake by frog skin and its modification by inhibitors of transepithelial sodium transport. J Physiol 228:221-239

11. Frizzell RA, Koch RM, Schultz SG (1976) Ion transport by rabbit colon. I. Active and passive components. J Membr Biol $27: 297-316$

12. Garty H, Edelman IS, Lindemann B (1983) Metabolic regulation of apical sodium permeability in toad urinary bladder in the presence and absence of aldosterone. J Membr Biol 74:1524

13. Helman SI, Nagel W, Fisher RS (1979) Ouabain on active transepithelial sodium transport in frog skin. J Gen Physiol $74: 105-127$

14. Hviid Larsen E (1973) Effect of amiloride, cyanide and ouabain on the active transport pathway in toad skin. In: Ussing $\mathrm{HH}$, Thorn NA (eds) Transport mechanisms in epithelia. Academic Press, New York, p 131

15. Kirk KL, Dawson DC (1983) Basolateral potassium channel in turtle colon: evidence for single file ion flow. J Gen Physiol $82: 297-313$

16. Kirk KL, Dawson DC (1983) Mechanism of epithelial lithium transport: evidence for basolateral $\mathrm{Na}: \mathrm{Na}$ and $\mathrm{Na}: \mathrm{Li}$ exchange. J Gen Physiol 82:497-510

17. Kirk KL, Halm DR, Dawson DC (1980) Active sodium transport by turtle colon via an electrogenic Na-K exchange pump. Nature 287:237-239

18. Koefoed-Johnsen $V$, Ussing HH (1958) The nature of the frog skin potential. Acta Physiol Scand 42:298-308
19. Lewis SA, Diamond JM (1976) $\mathrm{Na}^{+}$transport by rabbit urinary bladder, a tight epithelium. J Membr Biol 28:1-40

20. Moreno JH, Reisin IL, Rodriguez Boulan E, Rotunno C, Cereijido M (1973) Barriers to sodium movement across frog skin. J Membr Biol 11:99-115

21. O'Neil RG, Helman SI (1976) Influence of vasopressin and amiloride on shunt pathways of frog skin. Am J Physiol 23: $164-173$

22. Palmer LG, Edelman IS, Lindemann B (1980) Current-voltage analysis of apical sodium transport in toad urinary bladder: effects of inhibitors of transport and metabolism. J Membr Biol $57: 59-71$

23. Sarracino SM, Dawson DC (1978) Cation selectivity in active transport: properties of the turtle colon in the presence of mucosal lithium. J Membr Biol 46:295-313

24. Schultz SG (1981) Homocellular regulatory mechanisms in sodium-transporting epithelia: avoidance of extinction by "flush-through". Am J Physiol 241:F579-F590

25. Thompson SM, Dawson DC (1978) Sodium uptake across the apical border of the isolated turtle colon: confirmation of the two-barrier model. J Membr Biol 42:357-374

26. Thompson SM, Dawson DC (1978) Cation selectivity of the apical membrane of the turtle colon. J Gen Physiol 72:269- 282

27. Turnheim K, Frizzell RA, Schultz SG (1978) Interaction between cell sodium and the amiloride-sensitive sodium entry step in rabbit colon. J Membr Biol 39:233-256

28. Turnheim K, Thompson SM, Schultz SG (1983) Relation between intracellular sodium and active sodium transport in rabbit colon: current-voltage relations of the apical sodium entry mechanism in the presence of varying luminal sodium concentrations. J Membr Biol 76:299-309

29. Van Driessche W, Erlij D (1983) Noise analysis of inward and outward $\mathrm{Na}^{+}$currents across the apical border of ouabaintreated frog skin. Pflügers Arch 398:179-188

Received May 8/Accepted September 14, 1984 